\title{
DE SIERADENDOOS STILTE VAN DE NACHT VAN MIYOSHI KAGARI
}

In 1999 zagen mijn partner en ik deze 'Manhattan' doos op een tentoonstelling van hedendaagse toegepaste kunst in Tokyo. Wij waren gefascineerd door het ongewone thema en door de sprankelende uitstraling. Het zou vijf jaar en de nodige moeite vergen voordat deze doos aan onze verzameling kon worden toegevoegd.

\section{Ontwerp}

De vorm van de doos is gekozen om het ontwerp zo goed mogelijk tot zijn recht te laten komen (afb. 1). Het gaat om een hoog, zijdelings afgeplat model met twee lange en twee korte zijkanten. De bovenkant beschrijft een flauwe boog. De basis springt iets terug om het oppakken van de doos te vergemakkelijken.

Het deksel reikt bijna tot aan de basis (okibuta zukuri). Het voordeel daarvan is dat de voorstellingen niet onderbroken worden.

De doos zelf bestaat uit een diepe onderdoos met daar bovenop een half zo diepe gestapelde doos (afb. 2). Van binnen zijn de beide ruimtes bekleed met groen suède, omdat ze bedoeld zijn om er sieraden in op te bergen.

De doos is dermate perfect gemaakt dat het diepe deksel, als het losgelaten wordt, door de luchtweerstand wordt afgeremd en zachtjes naar de basis zinkt. Op beide lange zijden van de doos zijn stadsgezichten op het eiland Manhattan in New York afgebeeld: Midtown en Downtown, en dan vooral de gebieden met spectaculaire hoogbouw.

Op de Midtown kant is een viertal gebouwen gemakkelijk te identificeren (afb. 1). Links torent het Empire State Building hoog boven de omringende bebouwing uit. Direct eronder is de hoogbouw van het hoofdkwartier van de Verenigde Naties te zien en daarnaast de laagbouw met de zaal van de Algemene Vergadering, die te herkennen is aan het oplopende dak. Meer naar rechts valt het Chrysler-gebouw met zijn lange spits op en het Citigroup Center met het schuine dak. Het vrij hoge standpunt voor dit stadsgezicht moet aan de overkant van East River hebben gelegen, maar hoe je het ook met behulp van Google Earth probeert te vinden, de volgorde van de bouwwerken lijkt maar niet te willen kloppen. Wellicht is er ter wille van de compositie een beetje met de wolkenkrabbers geschoven?

Het standpunt voor het gezicht op het financiële district in Downtown Manhattan kan daarentegen wel vrij nauwkeurig worden teruggevonden en ligt aan de New Jersey kant van de Hudson rivier (afb. 3). Beeldbepalend zijn de reusachtige Twin Towers van het World Trade Center, die slechts 28 jaar hebben bestaan. Van ons bezoek in 1989 kan ik mij nog levendig herinneren hoe de grote vliegtuigen ver boven de torens vlogen, terwijl de helikopters voor het lokale zakenverkeer onder het niveau van bezoekersplatform langskwamen. 


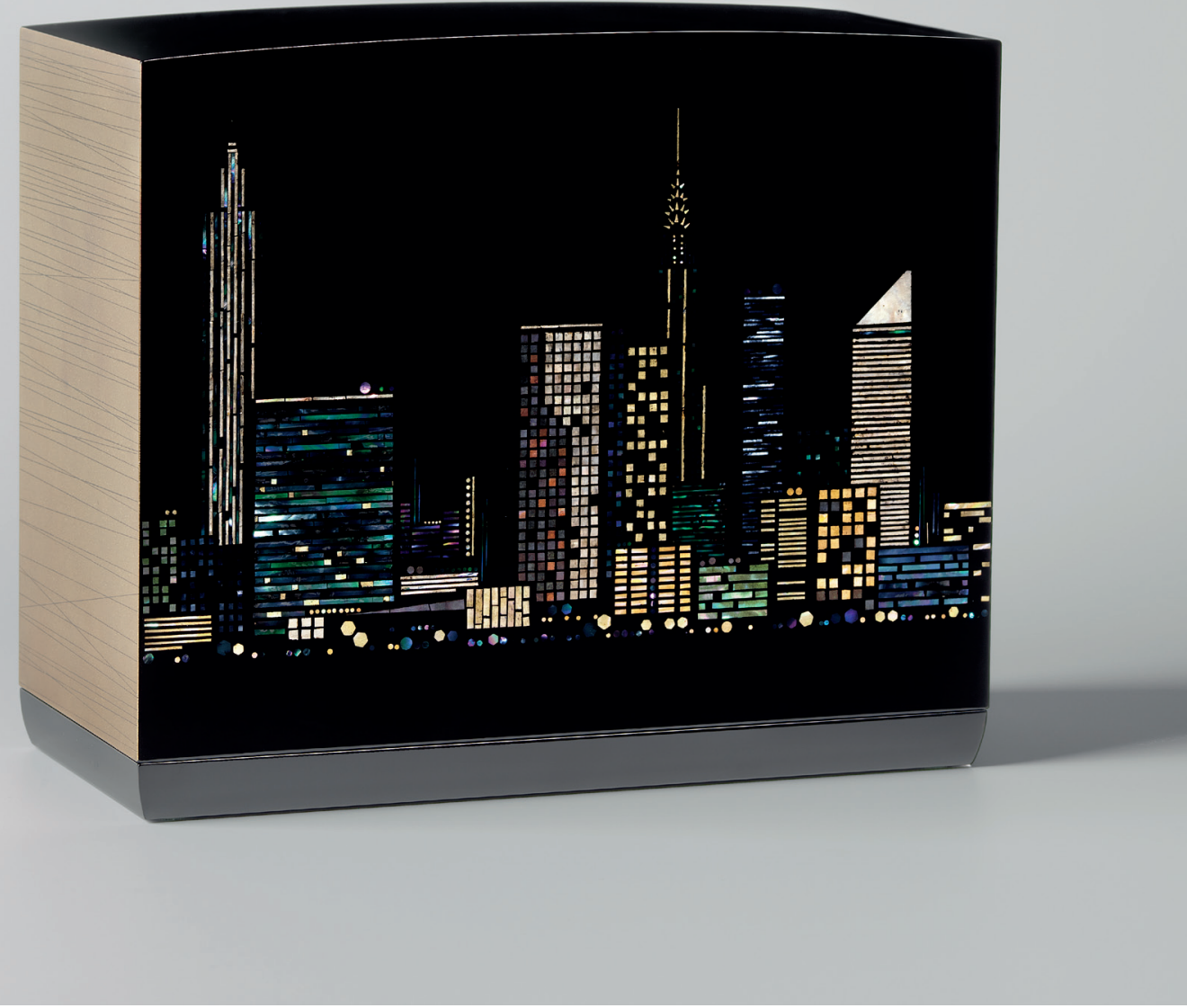

Afb. 1

Stadsgezicht op

Midtown Manhattan.

Sieradendoos Stilte

van de Nacht, 20,3 $\mathrm{x}$

$24,2 \times 11,2 \mathrm{~cm}$., Japan,

1999, Rijksmuseum

Amsterdam, inv. nr.

AK-C-2012-18, bruikleen

Jan Dees \& René van

der Star. 
De gebouwen die voor het World Trade Center staan behoren grotendeels tot het World Financial Center. Deze vormen, net als de meeste andere gebouwen die hier te zien zijn, onderdeel van Battery Park City, een recente stadsuitbreiding op een stuk aangewonnen land in de Hudson rivier.

Het zal duidelijk zijn dat de sieradendoos Manhattan bij nacht laat zien. De inktzwarte spiegelende ondergrond bedekt niet alleen de beide lange zijkanten maar ook de gebogen bovenzijde, die de nacht als het ware naar het hemelgewelf laat uitstrekken. De korte zijkanten zijn bestrooid met goudpoeder: representeren zij misschien de herinneringen aan het gouden licht van de dageraad en van de zonsondergang?

Wat er te zien is van de gebouwen zijn uitsluitend de verlichte ramen of de weerkaatsing van licht in glas of op metaal. Op straatniveau zijn talrijke lampen van het verkeer en van de staatverlichting zichtbaar. Omdat de stad gezien wordt vanaf de overzijde van de Hudson en de East River, die door zwarte vlakken worden gesuggereerd, overweegt de indruk van verstilling. Daaraan ontleent de doos zijn naam. De titel Seiya of Stilte van de Nacht staat op de houten verpakkingsdoos (tomobako) geschreven.

Op de bodem van de lakdoos is de signatuur 'Kagari' gegraveerd en met goudpoeder ingevuld (afb. 4).

\section{Laktechnieken}

De uitbeelding van de stadsgezichten is niet het resultaat van het 'sprenkelen' van goud- en zilverpoeder (makie), maar van nauwkeurig inlegwerk met bladgoud, bladzilver en dun parelmoer (iro kirigai noemt de kunstenares deze techniek).

Alle stukjes bladmetaal zijn bedekt met transparant, vrijwel kleurloos parelmoer om de reflectie te versterken. Sommige stukjes zilver zijn helder van kleur, maar andere zijn eerder grijs of blauwgrijs,wat het gevolg is van patineren. Zo werd een grotere schakering aan tinten bereikt. Het bladmetaal is in geometrische vormen uitgesneden: vierkantjes, rechthoekjes, zeshoekjes en rondjes.

\footnotetext{
Afb. 2

De gestapelde sieradendoos met een binnenbekleding van groen suède.
}

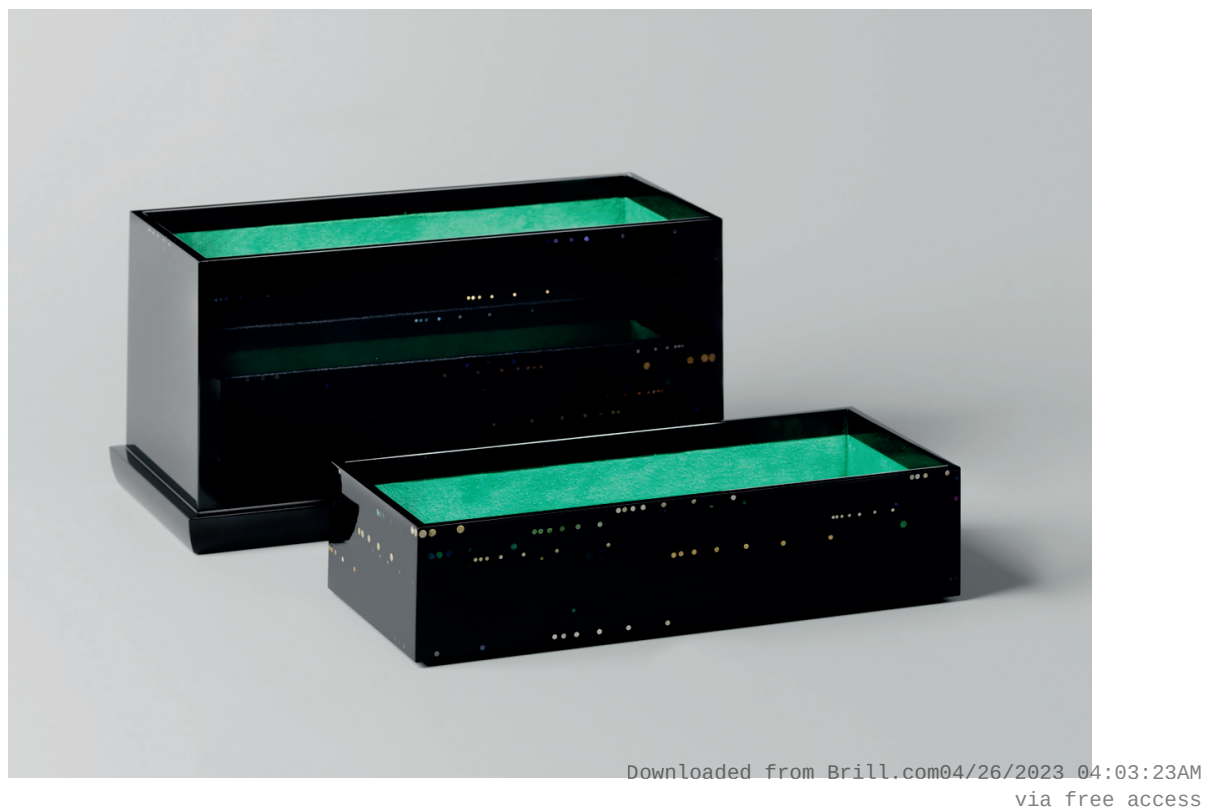




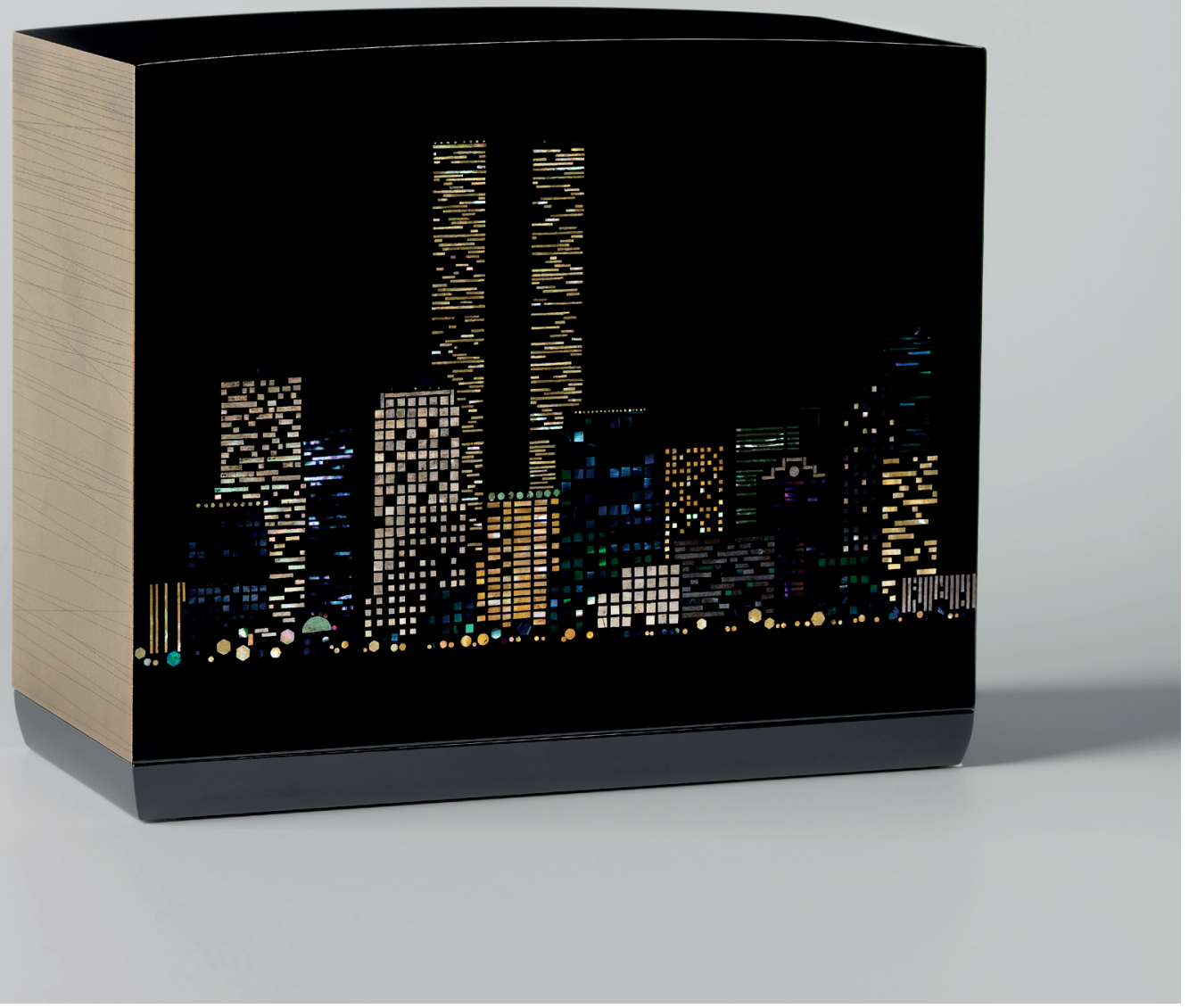

Afb. 3

Stadsgezicht op

Downtown Manhattan.

Sieradendoos Stilte

van de Nacht, 20,3 $\mathrm{x}$

$24,2 \times 11,2 \mathrm{~cm}$., Japan,

1999, Rijksmuseum

Amsterdam, inv. nr.

AK-C-2012-18, bruikleen

Jan Dees \& René van

der Star. 
Afb. 4 De signatuur 'Kagari'

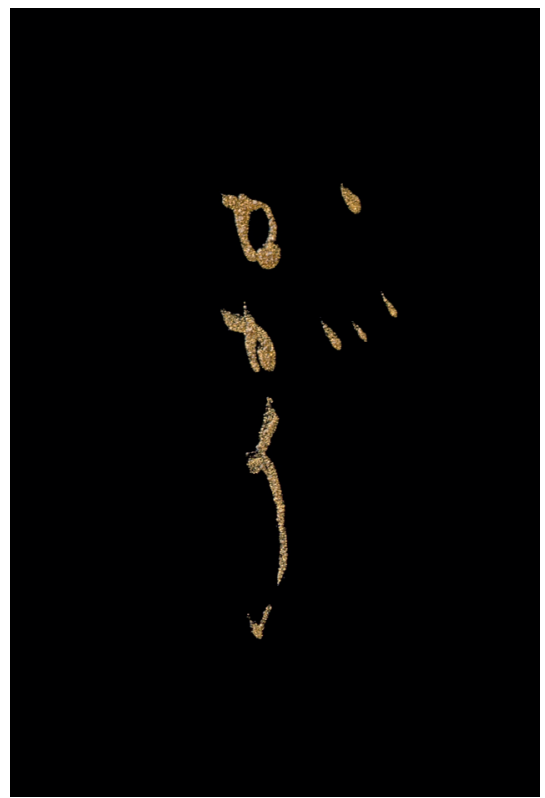

Het zeer dunne kleurige parelmoer, dat zonder ondergrond van bladmetaal is ingelegd,werd verkregen uit de iriserende binnenkant van de zeeoorschelp (Haliotis of awabi). Het toont eveneens een variëteit aan kleuren: groen, blauw, roze en paars. Dit flinterdunne parelmoer staat in de Japanse lakkunst bekend als aogai of 'blauwgroen parelmoer'. Sommige strips aogai, zoals die voor de antenne op de linker toren van het World Trade Center (waarschijnlijk op de foto nauwelijks zichtbaar), zijn extreem smal uitgesneden.

Inleg van metaal en parelmoer kan, mede afhankelijk van de dikte van het materiaal, op verschillende manieren plaatsvinden. Op deze sieradendoos ligt het aogai en het bladmetaal in het niveau van de zwarte ondergrond. Dat komt doordat de aangebrachte decoratie in het laatste stadium met enkele lagen zwarte lak is bedekt en vervolgens weer aan het oppervlak is gebracht door het schuren met slijpsteentjes (deze techniek is vergelijkbaar met de togidashi-methode in makie $^{1}$ ). Zodoende is de inlegdecoratie in het eindresultaat nauwelijks met de vinger te voelen. ${ }^{2}$

De beide korte zijkanten zijn uiteraard wel met goudpoeder bestrooid (makie); beide vlakken worden onderbroken door min of meer horizontale zwarte strepen.

\section{‘Urushi'}

Wat is Japans lak eigenlijk? Japans lak verschilt niet van de laksoorten die in China, Korea, Vietnam en Birma werden en worden toegepast. OostAziatische lak is een viskeus sap, dat gewonnen wordt uit de stammen en takken van de Toxicodendron vernicifluum (afb. 5 - de boom dankt zijn naam aan de heftige allergische huidreactie die de meeste mensen oplopen bij eerste aanraking met het sap). De wijze van tappen doet denken aan de manier waarop rubber wordt gewonnen. In Japan staat deze lak bekend onder de naam urushi, waarvan het meest essentiële bestanddeel het urushiol-molecuul is. 
Afb. 5

Urushi wordt als een sap uit de lakboom getapt door de bast van de stam of een dikke tak in te kerven. Tobita Yũzo is een ervaren tapper.

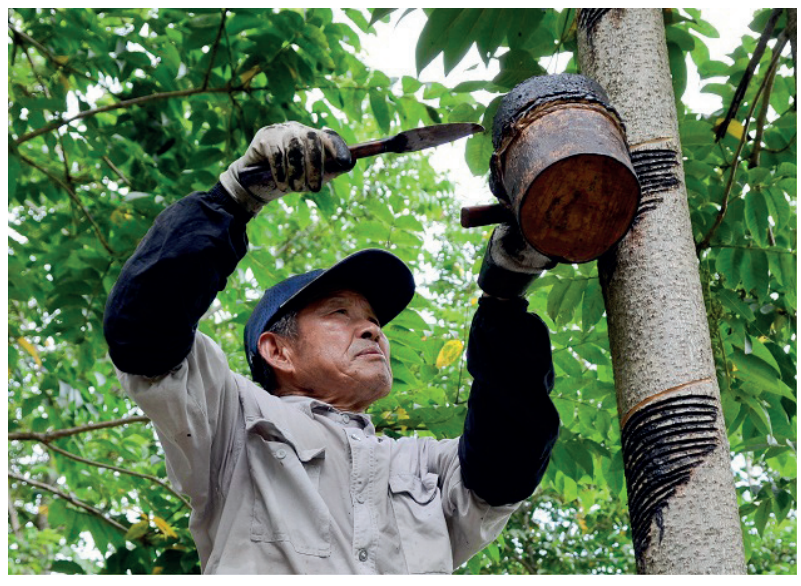

Urushi droogt uitsluitend indien het als een zeer dunne laag op de ondergrond wordt opgebracht, en dan nog alleen bij een vochtigheidsgraad van $85 \%$ en een temperatuur van 20 graden Celsius. In chemisch opzicht vindt dan, in aanwezigheid van zuurstof, polymerisatie van de urushiolmoleculen plaats, waardoor een sterke deklaag ontstaat. Omdat er dus niet zozeer sprake is van verdamping van vluchtige stoffen, is de term 'uitharden' juister dan de term 'drogen'. Dikkere lagen kunnen niet uitharden omdat onder het oppervlak het noodzakelijke zuurstof ontbreekt. Dit uitharden vind plaats in een speciaal daarvoor bestemde kast met de benodigde klimaatcondities: de muro.

\section{Miyoshi Kagari}

De kunstenares Miyoshi Kagari werd in 1954 geboren. Zij woont en werkt in Kamakura, een van de vroegere hoofdsteden van Japan. Tijdens haar studie filosofie ging zij in de leer bij de lakmeester Sasaki Ei (1934-1984), die een specialist was in parelmoerinleg. Zodoende is zij in de lakkunst beland. Sinds 1984 exposeert Kagari haar werk regelmatig op de omvangrijke Japanse Traditionele Kunsthandwerk Tentoonstelling (Nihon dentō kōgei ten), die elk jaar in het warenhuis Mitsukoshi in de Nihonbashi-wijk van Tokyo van start gaat, om vervolgens het land door te reizen. In 2004-2005 was zij gedurende een jaar artist in residence bij het Victoria \& Albert Museum in Londen. Stadsgezichten behoren al sinds het einde van de jaren 80 tot de vaste thema's van Miyoshi Kagari. In de periode 1988-1990 ging het veelal om anonieme steden met een uitgestrekte rommelige bebouwing die vanuit een hoog standpunt werden bezien. Tenminste drie van deze dozen hebben de titel Le Soir gekregen, naar een gedicht van Charles Baudelaire (1821-1867) waarin de eenzaamheid van de mens in de grote stad wordt beschreven. Een van deze dozen bevindt zich in de collectie van het Victoria \& Albert Museum. De latere dozen zijn hetzij abstracte stadsimpressies dan wel stadsportretten, niet alleen van New York, maar ook van Yokohama en andere metropolen. 


\section{Verwerving}

Het was op de Japanse Traditionele Kunsthandwerk Tentoonstelling in Mitsukoshi van 1999 dat mijn partner en ik Stilte van de Nacht voor het eerst hebben gezien. Als enige van de honderden objecten was deze doos voorzien van een bordje 'not for sale'. Raadselachtig, omdat er nooit dergelijke mededelingen bij de objecten staan en spijtig, omdat dit werk onze uitgesproken favoriet was.

Toen de doos een jaar later opdook in de tentoonstelling van hedendaagse Japanse lakkunst ter gelegenheid van 400 jaar handelsrelaties tussen Nederland en Japan in het Museum Jan van der Togt te Amstelveen, kregen wij aandrang om in actie te komen. Het Heinz Kaempfer Fonds, waar ik indertijd voorzitter van was, organiseerde bij deze tentoonstelling een symposium over de geschiedenis van de Japanse lakkunst. Onder de sprekers bevond zich een goede bekende van ons, professor Masumura Kiichirō, hoofd van de lakafdeling van de Geidai kunstuniversiteit in Tokyo. Zodoende kon ik via hem informeren of Miyoshi Kagari bereid was om de doos aan ons te verkopen. Aanvankelijk leek zij in te stemmen, maar toen kwam 9/11. Na de aanslag op de Twin Towers op 11 september van 2001 kon de kunstenares geen afstand meer doen van het werk dat haar zo na aan het hart lag. Haar aanbod om een tweede versie van Stilte van de Nacht voor ons te maken, wat een jaar in beslag zou nemen, liep op niets uit. Omdat ik Kagari toen inmiddels enkele malen in Japan had ontmoet, besloot zij uiteindelijk in 2004 om toch het oorspronkelijke werk aan ons af te staan; zij kwam het persoonlijk naar Nederland brengen. Tijdens de presentatie van een deel van onze lakverzameling in het Aziatisch Paviljoen bleek Stilte van de Nacht een publiekslieveling te zijn; de neusafdrukken op de vitrineruit vormden daarvan het onweerlegbare bewijs.

- In 1975 is Jan Dees geboeid geraakt door de lakkunst van Japan. Naast zijn werk als gastro-enteroloog verricht hij sinds de late jaren 80 in Europa en Japan onderzoek naar lakkunstenaars uit de periode 1890-1950. Hieruit is in 2007 het proefschrift Facing Modern Times: The revival of Japanese lacquer art 1890-1950 voortgekomen.

\section{Literatuur}

Jan Dees, De schrijfdoos Herfstplanten van Domoto Gosaburo, in: Aziatische Kunst 44/3 (2014), pp. 11-5

Japanese Contemporary Urushi Art Exhibition, Museum Jan van de Togt, Amstelveen, 2000. [tent.cat.]

Kagari Miyoshi, Honma Museum of Art, Sakata, 2001. [tent.cat.]

\section{Noten}

1. Aziatische Kunst 44/3 (2014): 13.

2. De inlegtechniek van iro kirigai is verwant aan de techniek van de Somada familie uit de Tokugawa-periode (1600-1868), alleen bedekten deze het bladmetaal niet met transparant parelmoer. 


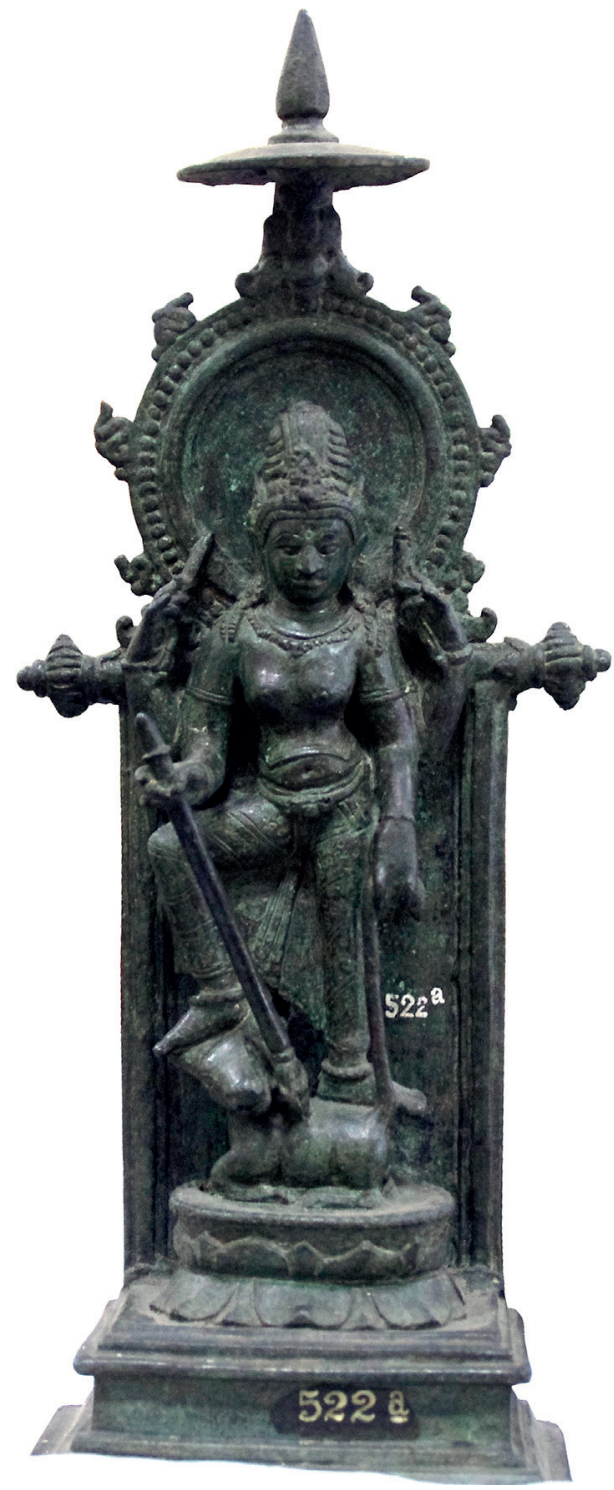

Fig. 1

Durga Mahisasuramardini, bronze, h. $29 \mathrm{~cm}$., reportedly found near Madiun, East Java, Indonesia, ca. 8th-gth centuries, National Museum of Indonesia, Jakarta, inv.nr. 522 a/2993/c. 17. Photograph: Mathilde Mechling, courtesy National Museum of Indonesia, Jakarta.

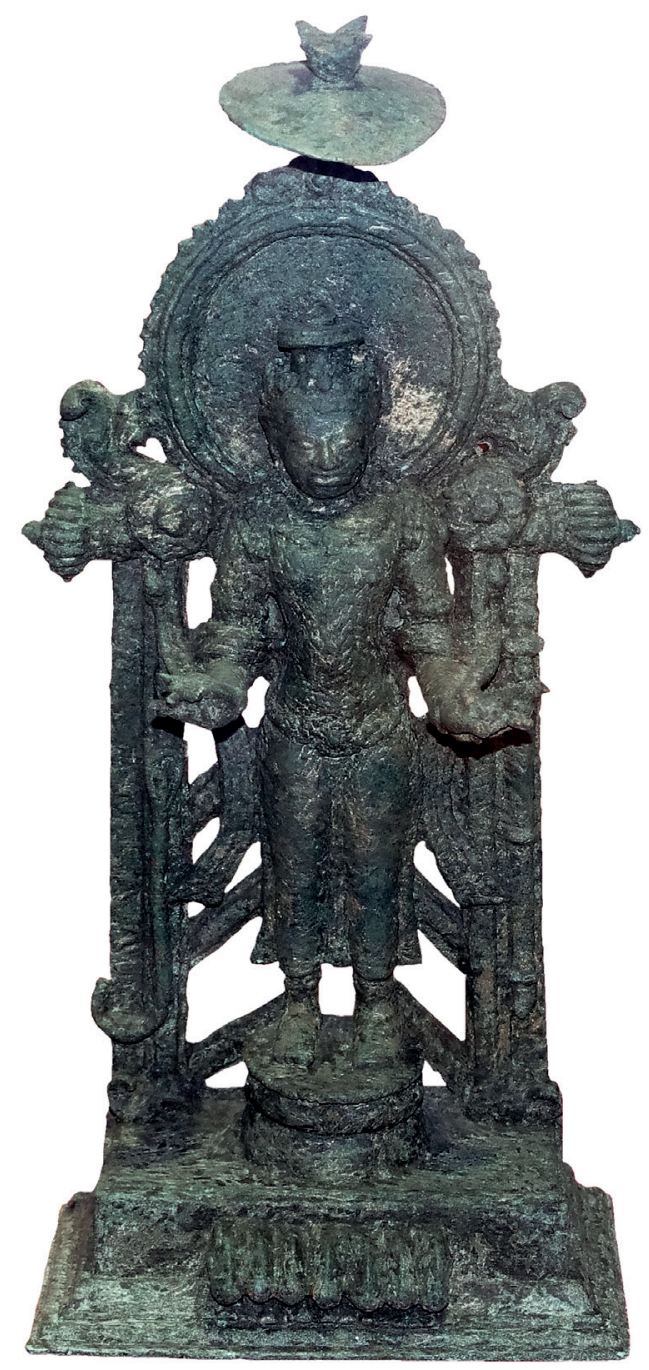

Fig. 2

Surya, bronze, h. ca. $30 \mathrm{~cm}$., found in Java, Indonesia (exact findspot unknown), ca. 8th-gth centuries, Museum Mpu Tantular, Sidoarjo. Photograph: Mathilde Mechling. 